\title{
A Imigração na Europa: a ação política da União Europeia para as migrações extracomunitárias ${ }^{1}$
}

\author{
Immigration in Europe: the European Union's political action for extra \\ migration
}

\author{
Wanise Cabral Silva \\ Nemo de Andrade do Amaral
}

\begin{abstract}
Resumo: Este artigo tem por objetivo fazer uma análise qualitativa da ação política regional da União Europeia para as migrações internacionais procedentes de terceiros Estados não membros do complexo institucional europeu. A normativa europeia estabelece os âmbitos do controle sobre a população extracomunitária. O controle de fronteiras, a integração social e a cooperação para o desenvolvimento constituem os eixos da política da União Europeia para as migrações. A normativa e o método utilizado pelos países da União Europeia no controle das migrações extracomunitárias resultam no relativo fracasso da ação política europeia. Nesse sentido, carecem de eficácia política e transformam um direito humano em ato delitivo.
\end{abstract}

Palavras-chave: União Europeia. Migrações Internacionais. Direitos Humanos.

\begin{abstract}
This article analyzes the EU regional policy for international migration, originating from the third parties and states not members of the European institutional complex. The European regulations laying down the scope of control over the foreign population, border control, social integration and development cooperation are the three main routes of migration policy in the EU. The rules and the method used in the control of migration by EU countries resulted in relative failure of European policy action in this direction, lack of political efficacy and transform a human right in crime.
\end{abstract}

Keywords: European Union. International Migration. Human Rights.

1 Recebido em: 15/02/2013.

Revisado em: 21/03/2013.

Aprovado em: 11/04/2013. 


\section{Introdução}

A União Europeia (UE) é o mais bem-sucedido projeto de regionalismo político no mundo, o foi no século passado e continua sendo no presente. Não há dúvidas de que esse complexo institucional comporta modelos avançados de democracia e de Estado de Direito historicamente forjados e desenvolvidos na Europa Ocidental. De fato, candidatar-se a membro pleno de direito exige mais do que compartilhar um espaço geográfico, mas a observância de uma série de quesitos, em especial dos valores, prioridades, interesses e objetivos que regem a União Europeia (UE).

Desde o Tratado Constitutivo da Comunidade Europeia até a sua reforma - o Tratado da União Europeia e o Tratado de Funcionamento da União Europeia de 2010 — , foram muitos os avanços no processo de integração: traçou-se a união aduaneira, desenvolveram-se instituições políticas próprias, estabeleceu-se a moeda única, adotou-se um modelo de cidadania, desenvolveu-se uma política exterior e de segurança comum. Enfim, constituiu-se em uma comunidade de nações, política, econômica e, de certa forma, socialmente organizada. Entretanto, a unidade europeia parece desmembrar-se em relação à política internacional para as migrações. Com competências divididas, a ação comunitária nesta matéria é limitada pela soberania dos Estados-Membros, que não encontram uma fórmula eficaz para a gestão global das migrações.

A construção do espaço europeu após a institucionalização do Acordo Schengen (2006), de 14 de junho de 1985, que delimitou as fronteiras externas da UE, iniciou no momento em que as migrações extracomunitárias se tornavam um problema para a Europa Ocidental. Desde a década anterior, marcada pela Guerra de Yom Kippur e pela crise petroleira, a Europa vinha aplicando uma "política de imigração zero" (ARANGO, 2005). Isso fez do Acordo um útil instrumento para a construção de uma fortaleza europeia, caracterizada pela debilidade das fronteiras interiores e pela harmonização dos controles e fortalecimento das fronteiras externas. A adesão ao Acordo Schengen permitiu o avanço das fronteiras externas da UE aos postos consulares europeus instalados em terceiros Estados. 
Erigiu-se uma "muralha" de difícil acesso para a população estrangeira de origem não europeia. Migrantes, potenciais migrantes e turistas padecem dos efeitos da Política Europeia de Segurança Comum (PESC), que define, grosso modo, os critérios da ação comunitária adotados para o tratamento das migrações internacionais. Contudo, é difícil imaginar uma política europeia única para as migrações, porque se repartem as competências entre os Estados, o que deixa à União a responsabilidade no estabelecimento de algumas diretrizes gerais, harmonizadas pela legislação nacional de cada um dos seus membros. Tampouco o enfoque global sobre migrações (UNIÃO EUROPEIA, 2006) - que, em dezembro de 2005, supunha importante avanço na concepção europeia ao envolver os países de origem e de trânsito dos fluxos na gestão das migrações - produziu resultados compatíveis com os valores humanitários difundidos pela União Europeia.

Na PESC encontramos limitado o método comunitário de gestão das migrações. É a partir dessa plataforma política que devemos buscar os elementos que nos ajudarão a entender o Pacto Europeu sobre Imigração e Asilo, instrumento que fornece as linhas da ação política arranjada para a gestão dos movimentos migratórios extracomunitários (UNIÃO EUROPEIA, 2008). Nesse sentido, pretende-se analisar a política migratória europeia, que se desenvolve em três linhas de ação: o controle dos fluxos de população, a integração social de migrantes e a cooperação para o desenvolvimento. Esses são os principais eixos políticos reunidos naquele Pacto, cujo alcance supera até mesmo os limites da competência europeia no assunto.

Partindo de uma perspectiva dos direitos humanos aplicada às migrações, pretende-se argumentar que, sob a lógica da segurança dos cidadãos europeus, vigora um rígido sistema de controle - que incide sobre os estrangeiros não comunitários de forma violenta, quebrantando direitos consagrados internacionalmente - sufocando o Estado de Direito e atentando contra os valores democráticos e humanitários difundidos pela Europa Ocidental. 


\section{Desenvolvimento: a integração política, o fechamento das fronteiras e os eixos do controle}

O processo de integração política na União Europeia é ainda incompleto, a sua estrutura tripartite admite a preeminência do caráter intergovernamental sobre o supranacional na construção de uma política comunitária para as migrações. No âmbito comunitário, o predomínio da intergovernabilidade no campo da ação política é funcional. Assim, o tratamento político outorgado às migrações internacionais - com a garantia de reserva à soberania nacional, que a priori pareceria perdida em função da adesão ao sistema comunitário — permite aos Estados-Membros manejar essas migrações de acordo com os interesses próprios de cada um deles, por exemplo, aqueles relacionados à cobertura de mão de obra dos seus mercados de trabalho e às questões demográficas. (UNIÓN EUROPEIA, 2010; 2006)

$\mathrm{Na}$ União Europeia, o caráter supranacional da comunidade aparece apenas em seu primeiro pilar institucional. Neste, o Parlamento, o Conselho e a Comissão Europeia limitam potencialmente a soberania dos Estados-Membros. Nos outros dois pilares, Política Exterior e de Segurança Comum (PESC) e Cooperação em Justiça e Assuntos de Interior (CJAI), as decisões são regidas pelo princípio da unanimidade, causador da competência entre os Estados.

A integração política na Europa supôs o fechamento das fronteiras externas do território que conforma a União Europeia e a abertura progressiva das fronteiras internas para a livre circulação dos cidadãos europeus. Em 1992, o Tratado de Maastricht criou a cidadania comunitária para os nacionais dos países membros, outorgando-lhes direitos políticos em âmbito comunitário (UNIÃO EUROPEIA, 2002). Então, consagrou-se a Europa dos cidadãos como um modelo inovador de regionalismo político, revigorado por uma Carta Constitucional em forma de Tratado ${ }^{2}$, livre e democrático para os seus membros, porém extremamente rígido e

2 O Tratado Constitucional, assinado em Roma pelos Chefes de Estado da União, em 29 de outubro de 2004, foi aprovado e ratificado por via parlamentar pela maioria dos Estados Membros. Na França e nos Países Baixos, o Texto foi submetido ao referendo 
oneroso para o resto do mundo. Isto é, a integração europeia aprofundou a distinção entre imigrantes comunitários, tornados cidadãos, e imigrantes estrangeiros; ou seja, o avanço em cidadania eliminou o primeiro tipo de imigração ao torná-la cidadã de pleno direito, mas o segundo tipo descendeu ou se estancou à condição de estrangeiros procedentes de terceiros países, personificados — seguindo a tradição do pensamento político ocidental — nos "turcos" de Maquiavel".

Essa nova geografia do poder impôs à União Europeia responsabilidades comuns em matéria de imigração. O Tratado de Amsterdã, de 17 de junho de 1997, contemplou o estabelecimento de uma política comum de imigração mediante a execução de programas quinquenais (UNIÃO EUROPEIA, 1997). O Programa de Tampere (1999-2004) e o Programa da Haia (2004-2009) reconheceram a questão da imigração como um problema para a Europa, que passou a atuar na gestão global dos fluxos migratórios, por meio da adoção de medidas de segurança que garantissem a liberdade de circulação territorial dos seus cidadãos, de um lado, e da elaboração de políticas de integração para os imigrantes residentes, do outro. Dessa forma, apresentava-se a segurança como o meio para alcançar a liberdade, e a nacionalidade como um critério indispensável para a cidadania europeia. O imigrante extracomunitário, estrangeiro, aparecia como o alvo dos mecanismos de segurança, podendo apenas gozar de liberdade de movimento e dos subsídios da integração social caso demonstrasse sua regularidade administrativa ante as autoridades policiais europeias.

No território europeu, o processo de ruptura das barreiras internas para a livre mobilidade de pessoas dentro do "espaço Schengen" acompanhou uma série de medidas de cooperação e coordenação entre os serviços policiais e judiciais dos Estados-Membros. Até mesmo o Reino Unido e a Irlanda, Estados que não pertencem a Schengen, negociaram as suas participações em matéria policial, judicial e penal (UNIÓN EUROPEIA,

e teve a sua aprovação denegada pela maior parte do eleitorado. (UNIÃO EUROPEIA, 2004)

3 De acordo com Bobbio (1994), desde Aristóteles até Hegel, houve sempre um "Estado Oriental" não europeu. Na história do pensamento filosófico ocidental foram inúmeras as tentativas de demonstração da existência de povos servis. Para Maquiavel, por exemplo, os turcos representavam ditos povos. 
2000; 2002). Quando feita a adoção do Tratado de Lisboa, em dezembro de 2007, ambos os Estados obtiveram o direito de exceção em matéria judicial e assuntos internos, regulando, de forma particular, os processos referentes a vistos, asilo e imigração (UNIÃO EUROPEIA, 2007). Do outro lado da fortaleza europeia, no exterior das fronteiras Schengen, consolidou-se um sistema de controle dos fluxos migratórios no interior dos países de emigração. Formou-se uma "muralha burocrática" de dupla face, caracterizada pela rigidez na aplicação (mesmo fora do seu território) dos critérios de seleção de pessoas consideradas aptas para circular pelo território da UE. Assim, do lado de fora de Schengen, o visto de entrada e circulação temporária obtido nos países de origem representa o primeiro ônus da livre circulação de pessoas. Outros mecanismos de controle foram também engenhados no interior dos países europeus, desde medidas de controle aplicadas em zonas fronteiriças até as políticas de cooperação bilateral e multilateral com os países de origem e de trânsito das migrações.

Sob a óptica de Schengen, dos Tratados Constitutivos e do Pacto Europeu sobre Imigração e Asilo, portanto, fica claro que a origem da ameaça reside do lado de fora da União. Esta ameaça seria a estrangeira, e se manifesta em forma de delinquência organizada e transnacional grave, terrorismo, tráfico de estupefacientes e de seres humanos, atos delitivos que consideraram vinculados às populações não cidadãs, em especial às migrações irregulares. A reforma dos Tratados da UE, em 2010, manteve essa concepção das migrações extracomunitárias como um problema para a Europa. As medidas comuns de luta contra a imigração irregular, a expulsão e a repatriação de irregulares e de migrantes antes regulares (mas que perderam a regularidade administrativa), encontram-se no texto do artigo 79 do Tratado de Funcionamento da União Europeia (UNIÃO EUROPEIA, 2010). Enfim, a normativa que institucionalizou Schengen e delimitou o espaço de liberdade, segurança e justiça tratou de criminalizar as migrações internacionais justificando o endurecimento das medidas de controle impostas às populações estrangeiras pela potencial ameaça que representam e, assim, legitimaram o benefício da livre circulação espacial para os cidadãos europeus e migrantes residentes. 


\subsection{Os Âmbitos do Controle}

O controle quase sempre aparece em forma de lei, e esta sempre manifesta uma ou mais formas de controle. Na União Europeia, o controle é um fim de per si na medida em que é o objetivo das políticas seletivas formuladas pelos Estados-Membros. O que aqui nos corresponde examinar, desde uma perspectiva de direitos humanos, emana de dentro de um espaço de segurança e de ordem pública ampla e transcende as fronteiras europeias. Ocorre tanto na origem como no destino dos fluxos migratórios e se apresenta como o primeiro dos três eixos da política de gestão das migrações internacionais. A integração social e a cooperação para o desenvolvimento são os outros dois eixos que, somados ao primeiro, compõem o quadro europeu da política de controle populacional.

Atualmente, o principal instrumento normativo em matéria de imigração na Europa é o Pacto Europeu sobre Imigração e Asilo, que institui diretrizes básicas para as políticas migratórias implementadas pelos Estados-Membros (UNIÃO EUROPEIA, 2008). O Pacto acompanha seu mecanismo de execução, o Programa de Estocolmo, que substituiu o da Haia, e estabelece as prioridades da União Europeia para o período 20102014. Cabe reforçar que essas prioridades respondem à trípode segurança, liberdade e justiça para cidadania europeia; mas, por outro lado, têm por objetivo o controle das migrações regulares e a luta contra a clandestinidade, observando as necessidades de cobertura das demandas de mercados de trabalho e de equilíbrio demográfico.

A Espanha é um bom exemplo disso: o país que qualificou seus cidadãos mediante os avanços no processo de democratização da educação também viu seus profissionais emigrarem para o Reino Unido por melhores condições de vida e trabalho. A solução espanhola se baseou na procura de mão de obra estrangeira mediante a adoção dos "Catálogos de ocupação laboral", que admitia uma migração contingente enviada ao país para sanar temporariamente os déficits que existiam em setores de saúde, serviços, etc. do seu mercado de trabalho. Essas medidas foram em parte criticadas quando se percebeu que essa migração de caráter temporário tendeu à permanência. Os resultados variaram entre a permanência definitiva em solo espanhol, o retorno voluntário aos países de origem, e 
a passagem à irregularidade administrativa daqueles indivíduos que não lograram renovar seus documentos de residência e trabalho. (MALAPEIRA, 2006)

Retomando o Programa de Estocolmo, que dispõe sobre: a execução de normas e práticas para o controle dos fluxos legais de população e a sua entrada e permanência em território europeu; normas e práticas relativas à construção de uma Europa de asilo; medidas relativas à integração de minorias étnicas, nas quais se encontram principalmente os imigrantes; políticas antirracismo e contra a discriminação; fortalecimento das fronteiras e a cooperação com os países de origem e de trânsito dos migrantes (UNIÃO EUROPEIA, 2008). Esses objetivos foram reunidos por Joaquím Arango (2005, p. 17-25) em três eixos principais: o controle, a integração e a cooperação internacional para o desenvolvimento, que trataremos de analisar. O Pacto e o Programa de Estocolmo compõem a estratégia europeia atual de gestão das migrações internacionais, que se realiza mediante a aplicação de um método de controle seletivo ainda variável em seus resultados, já que depende da experiência migratória, da legislação e dos interesses nacionais de cada um dos Estados-Membros da União.

\subsection{Laissez, Faire-Laissez Passer}

A máxima fisiocrata Laissez faire, laissez passer, adotada posteriormente pelo liberalismo econômico, reclamava a mínima intervenção do Estado na economia e a livre iniciativa de mercado, o que conduziria a uma sociedade mais igualitária à medida que a prosperidade aumentasse indefinidamente. Porém, se mal lograda, a tentativa poderia também conduzir à decadência da nação (ADAMS, 2001). Apesar da evolução do liberalismo em distintas correntes políticas e da abertura e expansão dos mercados a nível global (seguindo aquela lógica liberal), a expressão perde hoje sua validez com o advento da mundialização do trabalho, na qual a mão de obra surge como protagonista.

Hollifield (1992) utiliza a expressão "paradoxo liberal” para denominar a lógica econômica do liberalismo que demanda a abertura de mercados de trabalho no cenário do que, por conveniência, denominou- 
-se globalização, somada ao respectivo fechamento das fronteiras para os trabalhadores migrantes. Essa lógica revela uma grave fissura da filosofia liberal. Em outras palavras, mostra que as decisões políticas em matéria de imigração e trabalho não são tão liberais quanto o parecem, porque os Estados sim intervêm na economia - com o apoio de alguns setores sociais e empresariais - dispondo de estratégica e, convenientemente, de parâmetros utilitaristas para a seleção e inserção de mão de obra estrangeira em seus mercados de trabalho.

Até aqui vimos que o discurso europeu é contraditório, pois, ao mesmo tempo em que criminaliza as migrações procedentes de terceiros Estados, necessita delas para a cobertura de problemas particulares, de soluções não encontradas na mão de obra europeia.

Tal é a preocupação no sentido de controlar a entrada de migrantes que a União Europeia enfatiza a sua incapacidade de acolher a todos os que entram em seu território, ainda que proponha aos Estados-Membros o reforço na atração de mão de obra qualificada, que decidam as condições de entrada e permanência, e que fixem um número ideal de imigrantes regulares, considerando a possibilidade de esse número ser acordado com os países de origem das migrações. Até aqui é compreensível essa preocupação. De maneira que cada membro pode estabelecer os mecanismos de seleção de pessoas que considerarem oportunos, por exemplo, mediante a abertura de cotas de migrantes já citada no caso espanhol. A seleção de trabalhadores dá aos Estados o controle sobre suas fronteiras externas, remitindo-as à origem das migrações: a concessão do visto, o sistema de cotas de trabalhadores, os acordos bilaterais e multilaterais assinados com os países de origem, algumas políticas e programas de cooperação para o desenvolvimento, etc. Embora apresentem fórmulas e modelos diversos para a gestão da população potencialmente migrante, nem as todas as fórmulas logram resultados significativamente eficazes. Assim, o problema está no método utilizado e no discurso que o justifica.

Uma evidência da pouca eficácia na gestão dos fluxos de pessoas migrantes pode ser entendida pelo recente interesse da França e da Alemanha em retomarem os controles de suas fronteiras internas por meio da suspensão temporária de Schengen, com o objetivo de pôr fim à imigra- 
ção irregular enquanto persista a crise econômica e financeira na Europa ${ }^{4}$. A suspensão temporária de Schengen não é algo novo; de fato, alguns Estados-Membros retomaram o controle de suas fronteiras por curtos períodos de tempo e por razões de segurança pública. A questão levantada pelos Ministérios de Interior desses dois países pode ser uma evidência de que se encontra fragilizada a supranacionalidade na União Europeia, pois dois dos seus principais sócios anunciaram a Bruxelas a suspensão do Acordo, sem consulta prévia ao Parlamento e ao Conselho Europeu. Schengen torna-se, assim, um espaço questionável se os métodos utilizados na execução do Acordo são pouco efetivos com relação à gestão ordenada e humanitária dos fluxos. O Acordo não impede a evolução dos fluxos migratórios na Europa, causa ônus diversos à população migrante e põe à prova o direito à liberdade de circulação na Europa e no mundo. A precipitação de Paris e Berlin e as divergências de interesses em relação à reforma desse Acordo - intensificada pela discussão sobre a má situação econômica enfrentada por alguns países da zona do Euro - parece afundar a UE em uma grave crise de tono político-institucional.

Quanto aos mecanismos de seleção de pessoas, o visto se torna um importante instrumento de controle seletivo e se desenvolve em três níveis (MALAPEIRA, 2006). A obtenção de um simples visto de turismo respeita o cumprimento de uma série de requisitos para sua concessão ainda na origem - que podem partir da solicitação de entrada no espaço Schengen, passando pela apresentação de atestados de aptidão física e mental e de ausência de óbices penais até a demonstração de posse de uma importante soma financeira. Obviamente, a rigidez desse passo depende não só do que o viajante possa demonstrar, mas da situação migratória do país de sua nacionalidade. Na América Latina, por exemplo, Colômbia e Equador tiveram os seus vistos suspendidos por Espanha, que propôs o arranjo de acordos bilaterais para regular a circulação e residência temporária dos nacionais daqueles países em território espanhol (GERONIMI; CACHÓN; TEXIDÓ, 2004). O segundo nível de controle

\footnotetext{
4 A decisão arbitrária de ambos os países na suspensão do acordo foi anunciada por carta enviada à presidência da União Europeia. A questão reanimou o debate sobre a viabilidade de Schenguen e a sua eficácia na contenção dos fluxos migratórios. Um exemplo: Pérez (2012).
} 
transfere às companhias de transporte a comprovação de documentos e dos meios necessários para entrada no espaço Schengen. Em seguida surge a coordenação e a organização dos controles policiais em zonas fronteiriças. Em uma análise do caso espanhol, David Malapeira (2006, p. 47) afirma que o visto transfere ao Estado a capacidade de decisão, planificação e organização que lhe permite traçar os perfis desejados dos migrantes, ainda que o êxito na seleção não seja total devido a outros fatores, como a possibilidade de entrar e permanecer irregularmente e a existência de sujeitos com direitos constitucionalmente reconhecidos nos países de destino, por exemplo, os direitos derivados da dupla cidadania.

Além disso, o controle seletivo oferece resultados diversos e, em alguns casos, divergentes dos esperados pelos governos. Se, por um lado, tais medidas cooptam sujeitos realmente desejados pelos países de destino, por outro, colocam a perder o capital humano não desejado e retido nas fronteiras. Os controles fronteiriços, tais quais as políticas migratórias restritivas, não são capazes de pôr fim aos processos migratórios em função da rápida diversificação das rotas migratórias em um mundo altamente conectado. Por outro lado, é bem sabido que o turismo, além de representar uma importante fonte de ingressos para os Estados, constitui a principal porta de entrada de potenciais migrantes na Europa, o que torna ainda mais difícil as ações policiais em zonas de fronteira.

O ingresso no território Schengen é, assim, um concurso em que ganham somente aqueles que são considerados aptos para circular, residir e trabalhar na Europa. Para os que o direito de circulação significa nada - porque simplesmente não detêm esse direito - resta a sorte do ingresso clandestino, meio pelo qual se reproduzem as redes internacionais de tráfico de pessoas que encontram sua "clientela" no desespero dos rechaçados em fronteira.

Ao irromper o espaço Schengen, clandestinamente, o trânsito entre os países da UE é relativamente fácil devido à debilidade dos controles internos. Esse fenômeno explica, em parte, o desígnio da abordagem arbitrária de forças policiais sobre civis transeuntes nas cidades europeias. No destino, a irregularidade, mera falta administrativa, parece transformar-se em crime contra a ordem pública, e esse pode ser o único argumento 
válido para explicar o assombroso incremento do número de imigrantes irregulares em cárcere nos Centros de Internamento para Estrangeiros. (JARRÍN MORÁN; RODRIGUÉZ GARCÍA; DE LUCAS, 2012)

A privação da liberdade de circulação e as deportações em massa têm norma própria: a Diretiva de Retorno, que não dá conta dos abusos físicos e psicológicos sofridos por pessoas com direitos internacionalmente reconhecidos (UNIÃO EUROPEIA, 2003). A dificuldade em se mensurar os que não cumprem os critérios de seleção estipulados pelas nações europeias e que compõem o quadro da imigração irregular representa, em parte, o fracasso da política de controle e de gestão ordenada dos fluxos migratórios e o êxito da organização e do desenvolvimento das redes de tráfico de pessoas.

\subsection{Políticas de Integração para Imigrantes}

Em teoria, a integração aparece como um modelo melhorado de inclusão que pretende organizar social e politicamente a diversidade cultural em benefício da formação de sociedades multiculturais, coesas e livres da discriminação pela origem. No entanto, as políticas públicas formuladas pelos Estados-Membros, apesar das recomendações da União Europeia, derivam em estratégias de acomodação socioeconômica da diversidade cultural. A isso deram muitos títulos ao longo do caminho adaptação, acomodação, assimilação, etc. - em função dos tipos de políticas aplicadas e dos resultados por elas obtidos.

A UE tentou reforçar positivamente o conceito de integração como um processo bidirecional de aprendizagem que contemplasse a vontade de integrar-se do estrangeiro, mas que respondesse, sobretudo, às necessidades dos Estados-Membros.

$\mathrm{Na}$ comunidade europeia, as políticas de integração para imigrantes parecem estar relacionadas com o reforço das identidades nacionais europeias e dos controles migratórios para estrangeiros. $\mathrm{Na}$ medida em que se reconhece uma identidade comum - seja esta a europeia, expressa nos Tratados Constitutivos, seja as estatais, identificadas pelos signos, símbolos e significados nacionais - tende-se a traspassá-las aos sujeitos agregados, à diversidade assentada em um território distinto ao seu de ori- 
gem. Esse traspasso cultural pela via política pode gerar confusão ao implicar a sujeição do indivíduo estrangeiro àquelas identidades europeias, derivadas da herança cultural e religiosa da Europa Ocidental e somadas às identidades nacionais, suas histórias, valores e símbolos. Já que a UE delega aos seus sócios a competência na gestão da diversidade, os Estados a utilizam como meio de fomento ou reafirmação de suas identidades nacionais. Pretendem que o imigrante possa assimilar a identidade europeia conhecendo a identidade nacional do país em que reside. Não se mencionam, porém, em momento algum, os benefícios que podem ser obtidos do conhecimento das culturas estrangeiras. Nesse sentido, vejamos alguns exemplos de programas de integração para imigrantes empreendidos pelos países europeus, que parecem confirmar essa hipótese.

Os cursos de integração para imigrantes, promovidos a partir da lei de imigração alemã de 2005, centram-se em uma dura imposição do idioma (600 horas dedicadas), da cultura, da história, e do sistema político alemão (30 horas dedicadas) (TICONA, 2010). À primeira vista, todo o conhecimento oferecido pelo programa germânico pode ajudar os estrangeiros no processo de integração. O problema que apresenta esse sistema é o da simples adaptação do indivíduo, pois não há a contrapartida na aprendizagem alemã da cultura e história estrangeira.

Na França, a aprovação da Lei n. 2006-911, de 24 de julho (FRANÇA, 2006), sobre imigração e integração, deixou clara a obrigação contratual entre as partes: amar a pátria ou sair. A lei estabelece, em seu artigo 5: "Contrato de Acolhida e Integração (CAI)", a integração de imigrantes mediante a formação linguística e cívica sobre as instituições francesas e os valores republicanos.

Em outros Estados, como Bélgica e Espanha, a integração está fragmentada e fica regulada em âmbito local ou municipal, embora siga padrões similares aos dos alemães e dos franceses (GARCÍA AÑON, 2004). $\mathrm{Na}$ Espanha, o atual presidente do Governo e representante do Partido Popular, Mariano Rajoy, insiste na adoção de um contrato de integração ao estilo francês, com o objetivo de acomodar os imigrantes na sociedade espanhola, pelo menos, enquanto vigore o dito contrato (BÁRBULO; GARRIGA, 2008). García Añon (2004) considera que um dos problemas 
que apresenta esse modelo é de caráter metodológico, já que não existe homogeneidade nos planos de integração desenvolvidos por algumas Comunidades Autônomas. Quanto ao conteúdo, também não são coerentes, o que resulta em um problema estrutural de coordenação entre as diversas entidades encarregadas de pôr em prática esses planos.

Alguns dos atuais programas europeus de integração para estrangeiros não apresentam resultados eficazes, se considerarmos - como a UE tentou fazê-lo - que a aprendizagem deve ser bidirecional e o controle menos obtuso. A relação se assemelharia à de um patrão com os seus empregados, na medida em que estes passam por um processo de capacitação e, uma vez terminado o contrato, são obrigados a se retirarem do país de destino como se nele não houvessem construído toda uma vida. Assim, ainda que se busque na normativa europeia a relação bidirecional do processo de integração, as políticas nacionais de integração de estrangeiros contemplam apenas métodos de controle populacional unidirecionais pelos quais estão submetidos os sujeitos a padrões culturais rígidos, regidos por fortes doses de nacionalismo. $\mathrm{O}$ resultado disso é a eliminação do processo de integração em benefício do avanço de políticas utilitaristas e retrógradas de assimilação cultural, executadas em ambientes legitimamente democráticos.

Outro fator digno de menção é que a integração depende, em grande parte, da condição jurídica do estrangeiro. Não há integração sem a aquisição de direitos e deveres, portanto, nem todos os imigrantes são “integráveis". Na razão europeia, a integração só é possível para os sujeitos documentados, ou seja, em situação administrativa regular. Com isso, levantam-se duas razões pelas quais os processos de integração para imigrantes se encontram debilitados nas sociedades europeias. Primeiro, a existência de um grande número de políticas públicas nesse sentido resultam em uma enorme variedade de modelos e métodos aplicados. Em segundo lugar, nos países da União Europeia, a integração não é igual para todos os imigrantes extracomunitários, já que os programas contemplam somente aqueles estrangeiros que gozam do estatuto jurídico defini- 
do. Aos sujeitos à margem do ordenamento jurídico ${ }^{5}$, resta-lhes o retorno involuntário ${ }^{6}$, pois os imigrantes irregulares não são reconhecidos sujeitos de direito e, portanto, não participam efetivamente das políticas que promovem os processos de integração.

De acordo com o Professor Javier de Lucas (2006, p. 02), a imigração na Europa é um problema político e, portanto, a primeira condição da integração deve ser também de tono político. O reconhecimento político das migrações e a concessão de direitos para imigrantes que residem nos países europeus é um desafio atualmente, não sendo uma realidade possível para a maior parte da população imigrada nesse continente. Ainda que alguns países hajam outorgado o direito ao voto local e municipal mediante a adoção de acordos internacionais com os países de origem, o sufrágio em eleições nacionais e comunitárias está longe de ser algo factível. Só existe lá o cidadão europeu, a cidadania cosmopolita ainda não está em discussão. Em resumo, por origem e por sangue fica excluída a diversidade extracomunitária, e o sujeito político para a Europa não é mais do que o passaporte que consigo carrega.

\subsection{A Cooperação Internacional para o Desenvolvimento}

Parte fundamental da política de solidariedade da União Europeia é dedicada à cooperação internacional para o desenvolvimento, concertada

5 Em uma análise do caso espanhol, Solanes Corella (2001) afirma que a irregularidade dos imigrantes é favorecida pela permissividade das instituições espanholas, o que favorece os espanhóis em beneficio próprio e em vulnerabilidade da lei. Por outro lado, as dificuldades nas renovações dos documentos de residência e trabalho mantêm os imigrantes à margem do ordenamento jurídico espanhol.

6 Diretiva 2008/115/CE do Parlamento Europeu e do Conselho, de 16 dezembro de 2008, relativa a procedimentos e normas comuns para o retorno dos nacionais de terceiros países que se encontram ilegalmente em território europeu, aprovada pela Resolução Legislativa do Parlamento $n^{\circ}$ 0293/2008, de 18 de junho, por 662 votos a favor, 197 em contra, e 106 em branco. Basicamente, o documento parte do princípio de privação da liberdade, válido também para menores de idade, e da supressão dos direitos do ser humano. O apoio majoritário na aprovação do texto foi do grupo popular conservador, incluída a delegação espanhola e alguns liberais. O senhor Manfred Weber, eurodeputado do Parlamento, a considerou como o primeiro passo à consolidação de uma política comum de imigração para a UE. (UNIÃO EUROPEIA, 2008) 
com países terceiros que acordam estratégias de ação em diversas áreas - econômicas, financeiras e comerciais, políticas, jurídicas e sociais pelas quais se procura o desenvolvimento equilibrado e a relação harmônica e pacífica entre as nações.

As políticas de cooperação para o desenvolvimento vigoraram no pós-guerra da segunda metade do século passado e, apesar das distintas modalidades que assumiram ao longo do tempo, sustentaram-se no discurso da construção de um cenário mundial de equilíbrio e convivência pacífica entre as nações. Atualmente, o discurso é o mesmo: alcançar o desenvolvimento equilibrado e sustentável dos países por meio da cooperação internacional. Com respeito às particularidades de cada caso, a parte gorda da cooperação parece ser destinada ao comércio internacional e à inversão estrangeira. Isso quando a cooperação é vertical. Só a sua mínima parte se destina ao desenvolvimento sustentável de comunidades à borda da miséria. Mínima porque parece ser a parte da cooperação que doa/recebe menos recursos, geralmente para a consecução de programas e projetos do tipo socioeconômico, orientados ao avanço dos países em desenvolvimento. Essa vertente da cooperação entre agentes públicos e privados foi concebida na Europa também como um vetor da gestão de população potencialmente migrante, mesmo como mecanismo de arrefecimento dos fluxos migratórios. Portanto, o que aqui se discute não é a importância das políticas e programas em matéria de cooperação, mas a sua eficácia quanto à decisão de utilizá-la como instrumento de contenção de população emigrante.

As medidas em matéria de cooperação para o desenvolvimento se aplicaram às migrações como alternativa ao relativo fracasso do fechamento de fronteiras e da gestão dos movimentos de população estrangeira na Europa (ARANGO, 2005). Mas as ajudas econômicas que os países europeus destinam ao desenvolvimento não são suficientes para o avanço econômico dos países pouco industrializados, tampouco constituem um meio capaz de frear as migrações laborais. Se, por um lado, o desenvolvimento dos países do Sul não depende somente de ajudas econômicas alheias, por outro, o fim das migrações laborais não está diretamente relacionado à doação/inversão estrangeira nos locais de origem dos fluxos 
migratórios. Wihtol de Wenden (2000, p. 100) observa que, em longo prazo, o desenvolvimento potencial de países pouco desenvolvidos pode diminuir a emigração à medida que se consolide o livre comércio e o aumento da produção nesses países. Porém, em curto prazo - visão que predomina nas políticas atuais de cooperação - a aceleração de intercâmbios induzida pelo processo de desenvolvimento terá o efeito oposto, o de promover a emigração, tendo em conta as assimetrias nos âmbitos econômico, sociocultural e político entre os países de saída e os de destino das migrações. Essa autora toca o núcleo da questão: a diminuição das migrações para os países industrialmente desenvolvidos só é possível mediante a conquista de certo equilíbrio entre os planos econômicos, políticos e socioculturais de uns e de outros países. Portanto, o desenvolvimento no plano econômico não é condição suficiente para fazer diminuir os fluxos de população emigrante.

Tal e como está desenhada a estrutura sistêmica internacional, nos planos econômicos e políticos, o equilíbrio em desenvolvimento não só parece ser uma realidade muito distante da atual, mas também uma condição pouco provável, porque não é desejado pelos países do Atlântico Norte, principais potências mundiais. Os Estados cooperam e competem entre si. Como a cooperação se faz necessária, no plano político internacional, e a concorrência é a característica fundamental das atuais economias de mercado. No plano econômico, as ajudas do Norte são insuficientes, e até mesmo incapazes de produzir um estado real de equilíbrio entre as economias pouco industrializadas e as desenvolvidas. Sem risco de cair no determinismo histórico, as diferenças econômicas, políticas e socioculturais fazem parte da(s) história(s) do mundo, e não será por meio dessas ajudas que os homens superarão tais assimetrias. De acordo com Arango (2005, p. 18), as ajudas para o desenvolvimento "[...] cumprem uma função legitimadora, quando não de mera alimentação de boas consciências”.

As estratégias de cooperação entre países fomentam, assim, a mobilidade humana, à medida que se intensificam as relações entre dois ou mais países. Quanto mais intensa é a cooperação entre os estados, provavelmente maior será o movimento de população observado entre suas fronteiras. 
Como pode a cooperação arrefecer os movimentos migratórios se os resultados imediatos dessas políticas apontam para a intensificação dos fluxos de pessoas? Ao que parece, ainda não há fórmula eficaz conhecida. Houve a tentativa europeia de regular as migrações externas mediante a adoção de acordos e convênios bilaterais específicos na matéria (GERONIMI; CACHÓN; TEXIDÓ, 2004). Tal experiência rendeu frutos que foram aceitos com poucos ou sem impedimentos pelos países de origem e de trânsito das migrações. Os novos acordos de migração contemplam desde vantagens comercias para o país de origem até a concessão de direitos para a colônia de imigrados no país de destino.

Outros acordos mais antigos, conhecidos como acordos de colonização, em tempos de crise europeia normalizavam a entrada e residência de europeus em território latino-americano. A maior parte desses acordos foi assinada em relação bilateral por alguns países da atual União Europeia com os outros do Cone Sul da América Latina, ao longo de toda a segunda metade do século passado. O ainda vigente Acordo de Migração entre o Brasil e a Espanha, promulgado pelo Decreto n. 53.998, de 3 de julho de 1964 (BRASIL, 1964), concede amplos direitos de entrada, residência e trabalho à colônia espanhola no Brasil, mas, por omissão normativa ou ausência de reconhecimento recíproco, priva de direitos equivalentes os brasileiros radicados em território espanhol ${ }^{7}$. Brasil e Espanha não ratificaram as convenções relativas aos direitos das pessoas migrantes, tampouco existe norma de caráter bilateral que reconheça direitos de migração para os brasileiros que vivem na Espanha.

Os acordos de migração da primeira década deste século tratam de regular a entrada (temporária e seletiva) de trabalhadores migrantes nos países da UE. Por exemplo, os acordos celebrados pela Espanha com a

\footnotetext{
${ }^{7}$ A ausência de garantias à parte brasileira pode ser explicada, sucintamente, pela exiguidade de brasileiros emigrados à Espanha naquele momento histórico, porque o fluxo migratório era o inverso: a entrada de espanhóis no Brasil. Nos anos seguintes à década de 1990, período em que Brasil e Espanha começam a forjar uma aliança estratégica, a imigração brasileira cresce progressivamente em território espanhol à medida que se intensifica a "nova" relação hispano-brasileira. Dada à atemporalidade contextual da que goza o Acordo de Migração hispano-brasileiro, a sua vigência atual carece de qualquer justificativa razoável.
} 
Colômbia e com o Equador em 2001 (GERONIMI; CACHÓN; TEXIDÓ, 2004). Em ambos os casos aparece clara a intenção de reduzir as migrações de trabalhadores colombianos e equatorianos ao território espanhol, foi-lhes imposto rigidez no cumprimento dos supracitados requisitos de entrada, residência e trabalho, começando pela exigência do visto também para os seus turistas. Além do controle sobre os fluxos migratórios, esses acordos expõem a visão utilitarista com a qual é tratada a questão do trabalho estrangeiro na Europa (GERONIMI; CACHÓN; TEXIDÓ, 2004). Por último, cabe menção aos convênios que compõem o quadro geral das áreas de cooperação - em turismo, educação, ciência e tecnologia, comércio internacional, segurança social mútua e assistência jurídico-penal, sanitária, etc. - que apenas tocam em assuntos de migrações internacionais, mas que sobre estas impactam profundamente e quase sempre de forma negativa.

\section{Conclusões}

A política europeia para as migrações internacionais, definida pelo Pacto Europeu sobre Imigração e Asilo em três campos de ação - o controle dos fluxos de população, a integração dos migrantes e a cooperação para o desenvolvimento - , resultam no relativo fracasso europeu da gestão da população estrangeira migrante. Tanto as medidas seletivas de captação e controle de trabalhadores migrantes adotadas pelos membros da União Europeia como as políticas migratórias restritivas que regulam a entrada e permanência de pessoas no espaço Schengen permitem o aparecimento de novas e diversificadas rotas migratórias clandestinas e reproduzem a irregularidade administrativa como resultado do endurecimento dos critérios de seleção. A criminalização da imigração irregular, com o objetivo de garantir um espaço de segurança, liberdade e justiça, criou também condições oportunas para a ação delitiva das redes internacionais de tráfico de pessoas e demais violações de direitos humanos.

A estratégia europeia dos programas de integração para imigrantes implanta um fragmentado sistema de educação de caráter unidirecional, no qual predomina uma forte dose de reforço das identidades nacionais 
dos estados membros, onde os diversos métodos empregados subsomem a integração em uma série de técnicas difusas de acomodação de sujeitos às normas e interesses nacionais. Isso resulta em fracasso das políticas públicas para a integração, pois o modelo empregado admite a manutenção de prejuízos sobre a diversidade. De um lado, se desconhece as culturas estrangeiras e, do outro, se veem eliminados padrões culturais próprios pelo sistema de assimilação. Há o fomento do assentamento de estrangeiros em bairros para imigrantes, mas os novos guetos cumprem melhor a função de integrar o sujeito na sociedade de destino do que as políticas que deveriam promover a integração.

Por outro lado, a cooperação para o desenvolvimento se vê limitada pelos interesses que a promovem. Ainda que a cooperação com a finalidade de apaziguar os movimentos migratórios possa haver obtido algum êxito em relação ao avanço econômico de pequenas comunidades migrantes no sul do Mediterrâneo, os movimentos não pararam, tornando questionável a sua aplicação em zonas mais distantes de origem dos fluxos. Provavelmente o avanço econômico proveja o potencial migrante dos meios materiais de que necessita para o seu empreendimento internacional.

As grandes distâncias somadas à política restritiva dos requisitos de entrada e residência nos países europeus constituem um obstáculo quase insuperável para a extrema pobreza, em que se consomem os escassos recursos da cooperação para o desenvolvimento. Então, o incremento de recursos pessoais derivados do sucesso das políticas de desenvolvimento aumentam as probabilidades de ocorrência do projeto migratório. De fato, a maior parte dos migrantes que recorreram grandes distâncias geográficas não constituíam na origem os filhos da extrema pobreza que aquelas políticas prometem resolver. Se admitirmos, à exceção do caso mediterrâneo e das particularidades do refúgio, que os imigrantes hoje radicados na Europa entraram, em sua maioria, em situação de turistas tornados overstayers $^{8}$, devemos concluir que a cooperação para o desenvolvimento potencializa os movimentos migratórios entre os países.

${ }^{8}$ Palavra que representa, na concepção europeia, o sujeito que passou de uma situação regular à irregularidade administrativa adquirida após o vencimento do visto de turista. 
Tendo em vista os princípios democráticos e humanistas do Direito Internacional Europeu, a observância à normativa internacional dos Direitos Humanos - textos cuja cita aparece constantemente nos Tratados constitutivos da União Europeia - , a ação externa desta comunidade política é de conteúdo e eficácia questionáveis em matéria de migrações internacionais. A contradição entre o discurso e a prática europeia mostra que é possível violar aqueles princípios, debilitar os Direitos Humanos e produzir efeitos contrários aos resultados esperados pela gestão internacional das migrações.

\section{Referências}

ADAMS, Ian. Political ideology today. Manchester: Manchester University Press, 2001.

ARANGO, Joaquim. Dificultades y dilemas de las políticas de inmigración. Revista ARBOR, Madrid, CLXXXI, n. 713, mayo-junio, 2005.

BÁRBULO, Tomás; GARRIGA, Josep. Rajoy quiere obligar a los inmigrantes a firmar un “contrato de integración”. El País, Madrid, 7 fev. 2008. Disponível em: < http://elpais.com/diario/2008/02/07/ espana/1202338806_850215.html>. Acesso em: 20 nov. 2010.

BOBBIO, Norberto. A Teoria das formas de governo. Tradução de Sergio Bath. Brasília: Editora Universidade de Brasília, 1994.

BRASIL. Decreto n. 53.998, de 3 de julho de 1964. Acordo de Migração celebrado entre Brasil e Espanha. Disponível em: $<$ http://www.itamaraty. gov.br>. Versão em espanhol disponível em: $<$ http//:www.aranzadi.es $>$. Acesso em: 20 dez. 2010.

DE LUCAS, Javier. La ciudadanía para los inmigrantes: una condición de la Europa democrática y multicultural. Revista de Filosofía Eikasia, Oviedo, Instituto de Estudios para la Paz y la Cooperación, n. 4, p. 1-19, mayo, 2006. 
PÉREZ, Claudi; MORA, Miguel. París y Berlín quieren recuperar el control de fronteras sin depender de Bruselas. El País, Madrid, 20 abr. 2012. Disponível em: < http://internacional.elpais.com/ internacional/2012/04/19/actualidad/1334854425_577479.html $>$. Acesso em: 20 abr. 2012.

FRANÇA. Loi n. 2006-911, du 24 julliet de 2006. Relative à l'immigration et à l'intégration. Disponível em: $<$ http//:www.legifrance. gouv.fr>. Acesso em: $1^{\circ}$ set. 2010.

GARCÍA AÑON, José. Integración social de los inmigrantes y la concreción de sus derechos en los planes autonómicos. In: MARTÍN, Laura Miraut. (Ed.) Justicia, Migración y Derecho, Madrid: Dykinson, 2004.

GERONIMI, Eduardo; CACHÓN, Lorenzo; TEXIDÓ, Ezequiel. Acuerdos bilaterales de migración de mano de obra: estudios de caso. Revista de Estudios sobre Migraciones Internacionales, Ginebra, n. 66, Organización Internacional de Trabajo, 2004.

HOLLIFIELD, James. Immigrants, Markets and States. Cambridge: Harvard University Press, 1992.

JARRÍN MORÁN, Adriana; RODRÍGUEZ GARCÍA, Dan; DE LUCAS, Javier. Lós centros de internamiento de extranjeros em España: origen, funcionamiento e implicaciones jurídico-sociales. Documentos CIDOB Migraciones, Barcelona, n. 26 octubre, Barcelona Centre for International Affairs, 2012.

MALAPEIRA, David M. La evolución del sistema de control migratorio de entrada en España. In: AJA, Eliseo; ARANGO, Joaquim (Ed.). 20 años de inmigración de España: perspectiva jurídica y sociológica. Barcelona: Fundación CIDOB, 2006.

SOLANES CORELLA, Ángeles. Sujetos al margen del ordenamiento jurídico: los inmigrantes sin papeles. In: DE LUCAS, Javier; PEÑA, Salomé; SOLANES CORELLA, Ángeles (Coord.) Trabajadores Inmigrantes. Germania: Valencia, 2001. 
TICONA, Tatiana. Las contradicciones de la política de integración alemana. Opinión CIDOB, n. 55, Barcelona, 12 de enero de 2010. Disponível em: <http://www.cidob.org/publicaciones/opinión>. Acesso em: $1^{\mathrm{o}}$ set. 2010 .

UNIÓN EUROPEA. Comisión de las Comunidades Europeas.

Comunicación 379 final. Propuesta de Directiva del Parlamento y del Consejo relativa a las condiciones de entrada y residencia de nacionales de terceros países para fines de empleo estacional, Bruselas, 13 de jul. 2010. Disponível em: $<$ http://eur-lex.europa.eu/LexUriServ/LexUriServ. do?uri=COM:2010:0379:FIN:ES:PDF>. Acesso em: 10 set. 2011.

UNIÓN EUROPEA. Comisión de las Comunidades Europeas.

Comunicación 94. Libro Verde: Frente a los cambios demográficos, una nueva solidaridad entre generaciones, Bruselas, 16 mar. 2005. Disponível em: < http://eur-lex.europa.eu/LexUriServ/site/es/com/2005/ com2005_0094es01.pdf. Acesso em: 15 set. 2010. Acesso em 2 out. 2011. UNIÓN EUROPEA. Comisión de las Comunidades Europeas. Comunicación (2006) 571 final. El futuro demográfico de Europa: transformar un reto en una oportunidad. Bruselas, 12 de oct. 2006. Disponível em: <http://europa.eu/legislation_summaries/employment and_social_policy/situation_in_europe/c10160_es.htm $>$. Acesso em: 11 set. 2011.

UNIÓN EUROPEA. Comisión de las Comunidades Europeas.

Comunicación 735. El planteamiento global sobre la migración un año después: hacia una política global europea en materia de migración. Bruselas, 2006. Disponível em: $<$ http://eurlex.europa.eu/LexUriServ/LexUriServ.do?ur $\mathrm{i}=\mathrm{COM}: 2006: 0735: \mathrm{FIN}: \mathrm{ES}: \mathrm{PDF}>$. Acesso em: 17 nov. 2011.

UNIÓN EUROPEA. Consejo Europeo. Decisión (2000/365/CE) del Consejo sobre la solicitud de Reino Unido de Gran Bretaña e Irlanda del Norte de participar en algunas de las disposiciones del acervo de Schengen. Diario Oficial de las Comunidades Europeas, Bruselas, 1 jun. 2000. p. 43-47. Disponível em: <http://eurlex.europa.eu/LexUriServ/ LexUriServ.do? uri=CELEX:32000D0365:ES:NOT>. Acesso em: 10 out. 2011. 
UNIÓN EUROPEA. Consejo Europeo. Decisión 192 del Consejo sobre la solicitud de Irlanda de participar en algunas de las disposiciones del acervo de Schengen. Diario Oficial de las Comunidades Europeas, Bruselas, L. 64, p. 20-23, 7 mar. 2002. Disponível em: <http://eurlex. europa.eu/LexUriServ/LexUriServ.do?uri=CELEX:32002D0192:ES:N OT>. Acesso em: 10 out. 2011.

\section{UNIÃO EUROPEIA. Conselho Europeu. Pacto Europeu sobre}

Imigração e Asilo, n. 13440/08, Bruselas, 24 de set. 2008. Disponível em: <http://europa.eu/legislation_summaries/justice_freedom_security/ free_movement_of_persons_asylum_immigration/j10038_pt.htm>. Acesso em: 10 set. 2011.

UNIÃO EUROPEIA. Tratado que estabelece uma Constituição para a Europa. Jornal Oficial da União Europeia, ano 47, 16 dez. 2004. Disponível em: <http://eurlex.europa.eu/JOHtml.do?uri=OJ\%3AC\%3A2 004\%3A310\%3ASOM\%3APT\%3AHTML>. Acesso em: 10 set. 2011.

WIHTOL DE WENDEN, Catherine. ¿Hay que abrir las fronteras? Barcelona: Edicions Bellaterra, 2000.

Wanise Cabral Silva é Doutora em Direito pela Universidade Gama Filho (UGF), Mestre em Direito pela Universidade Federal de Santa Catarina (UFSC) e Graduada em Direito pela Universidade Federal do Espírito Santo (UFES). Professora do Programa de Pós-Graduação em Direito Constitucional e da Graduação da Faculdade de Direito da Universidade Federal Fluminense (UFF). E-mail:wanisecabral@hotmail.com.

Endereço profissional: Universidade Federal Fluminense. Faculdade de Direito. Rua Presidente Pedreira, 62. Ingá, Niterói/RJ. CEP: 24.210-470.

Nemo de Andrade do Amaral é Doutorando em Derechos Humanos, Democracia y Justicia Internacional pela Universidade de Valência, Espanha. Pesquisador bolsista do Instituto de Pesquisa Econômica Aplicada (IPEA). E-mail: nemoamaral@hotmail.com. 
Endereço profissional: Instituto de Pesquisa Econômica Aplicada. Diretoria de Estudos em Relações Econômicas e Políticas Internacionais. SBS, Quadra 1, Bloco J, Ed. BNDES/Ipea, $8^{\circ}$ andar, sala 825. Brasília/DF. CEP: 70.076-900. 